\title{
Flexible design of urban drainage systems: demand led research for Hamburg-Wilhelmsburg
}

\author{
Jochen Eckart • Heiko Sieker • \\ Kala Vairavamoorthy $\cdot$ Kamal Alsharif
}

Published online: 21 October 2011

(C) Springer Science+Business Media B.V. 2011

\section{Introduction: the need for flexible design in urban drainage systems}

With increasing global change pressures (urbanisation, climate change, etc.), cities of the future will experience difficulties in managing their water supply, drainage and wastewater. These global change pressures were addressed by SWITCH, an EU 6th Framework research project that developed technological and socio-economic solutions for the sustainable management of water in the city of the future. The project involved 32 partners from across the globe working directly with stakeholders in 12 demonstration cities. An important component of SWITCH was gathering together stakeholders that were involved with, or interested in, urban water management. These multi-stakeholder learning alliances guided and

J. Eckart $(\bowtie) \cdot K$. Vairavamoorthy $\cdot$ K. Alsharif Patel School of Global Sustainability, University of South Florida, 4202 East Fowler Avenue, CGS 101, Tampa, FL 33620, USA

e-mail: jocheneckart@gmx.de

K. Vairavamoorthy

e-mail: vairavk@usf.edu

K. Alsharif

e-mail: kalshari@cas.usf.edu

\section{H. Sieker}

Ingenieurgesellschaft Prof. Dr. Sieker mbH,

Rennbahnallee 109A, 15366 Hoppegarten, Germany

e-mail: h.sieker@sieker.de supported SWITCH on implementing research and demonstration activities, by taking account of local problems and needs (Vairavamoorthy 2009b).

One of the main cities involved in SWITCH was Hamburg, Germany whose Learning Alliance (LA) included members from administration, infrastructure providers, NGOs, citizen groups and scientists from the fields of urban water management, urban planning and environmental protection. A strategic planning process was undertaken with the Hamburg LA (van der Steen and Howe 2009) for the district of HamburgWilhelmsburg. This strategic planning process (supported by researchers from SWITCH), identified several challenges for the city of Hamburg, particularly with urban drainage issues (Langenbach 2008).

In relation to urban drainage, the Hamburg LA identified two main change pressures that would have the most severe impact on the performance of the conventional and sustainable urban drainage systems.

- Urban development and the associated increase of impervious area in Hamburg-Wilhelmsburg.

- Global climate change and its impact on future rainfall patterns (increase in rainfall intensity).

The projections for these two change pressures are plagued with uncertainties, making accurate deterministic forecasts impossible. It is predicted that the runoff will change, but reliable forecasts about the time and extent of change are missing, and these severe uncertainties cause difficulties when developing an appropriate urban drainage strategy for 
Hamburg-Wilhelmsburg. In response to this, the Hamburg LA recognised that there is a need to develop flexible urban drainage systems that can cope with uncertainties and have the ability to adapt to changing requirements (Sieker 2008a; Vairavamoorthy 2009a). Even though the idea of flexible design for urban drainage systems is already discussed in the technical literature (Ashley et al. 2007; Kluge and Libbe 2006; Maharjan et al. 2009; Schmitt 2006), the majority of the Hamburg LA members did not fully understand the concept of flexibility. They argued for the need to demystify this concept by presenting it in a practical, tangible and operational context.

Based on the interactions with the Hamburg LA, it was clear that research should be undertaken to make the concept of flexibility more tangible for urban drainage. In response to this, the following research questions were formulated:

- What does flexibility mean in relation to urban drainage?

- How can flexibility be quantified and measured for urban drainage systems?

\section{Flexible design for urban drainage systems}

Due to confusion on the part of the Hamburg LA, regarding flexibility and other related concepts dealing with future uncertainties like robustness or resilience, there was a need for a simple and precise definition of flexibility. Three core principles of flexibility were highlighted. Firstly, the objective of flexible design is to overcome systemic internal or external changes, which affect the system performance. According to de Neufville and Cardin (2008) flexibility should guarantee good long-term performance of a system by protecting it against downside effects and by exploiting upside opportunities. Secondly, the ability to modify a system so that it adapts to future demands, is offered by so-called flexibility options. The flexibility options provide the system manager the right, but not the obligation to change the system during operation. Thirdly, flexibility should guarantee system adaptations, based on changing conditions, with minimal effort so that the system adaptations could be achieved with minimal costs over a short time-period. Based on these principles, flexibility is defined as 'the ability of urban drainage systems, to use their active capacity to act and to respond to relevant alterations of the input factors or system objectives in a performance-efficient, timely and cost-effective way' (Eckart et al. 2010).

\section{Measurement of flexibility for urban drainage systems}

The LA members require methods to illustrate the benefits of flexible design and to assess the flexibility of alternative solutions. The LA consists of a diverse group of stakeholders with different requirements on the measurement approach. Some stakeholders require metrics, which can be applied quickly and easily. Another group of stakeholders require metrics that provide more detailed information to support complex decision-making processes. To address the different demands of the LA members, two approaches for the measurement of flexibility were developed within the SWITCH project (Peters et al. 2010). The measurement approaches differ from each other in the amount of work required as well as the detail-level of the results. The COFAS (Comparing the Flexibility of Alternative Solutions) method is a pragmatic approach to measure flexibility; it provides simple results and is designed for quick project assessment. The other approach is more complex, it offers a micro-level analysis of flexibility but it requires a large amount of work.

\subsection{COFAS}

In the COFAS approach, the indicator 'homogeneity of performance' is used for the measurement of flexibility (Peters et al. 2010). The indicator is selected based on the assumption that the higher the homogeneity of performance for different objectives of the system, the higher the flexibility. Homogeneity is represented by the standard deviation of the performance for different objectives (Helm et al. 2009). Therefore, unspecialised and multi-purpose systems offer high flexibility against future uncertainties because they offer a wide variety of performances to react to altering requirements. This approach offers LA members a quick and easy assessment of flexibility but the indicator only represents a static characteristic of the system, neglecting the dynamic future development. 
The COFAS method includes the following steps:

- Initially, a regular utility value analysis is performed. The objectives, related indicators and utility functions for the urban drainage system are defined.

- With a hydrological model, officials ascertain the performance of the urban drainage with regard to these indicators. Based on these results, officials calculate the utility value for the single objectives, as well as the weighted average value.

- Finally, in addition to the average utility value for the different indicators, the homogeneity is also calculated. The homogeneity is represented by the standard deviation for the different indicators. As a result, the higher the homogeneity of an alternative solution, the higher the flexibility.

To discuss the complex results with LA members, a good visual image is required to ensure that they comprehend the results. In the COFAS method the homogeneity and the flexibility is visualized in a sector diagram where the radius of a sector represents the utility value, while the aperture angle shows the weighting factor. The sector diagram in Fig. 1 illustrates the system performance for different objectives. In the conventional drainage system only two out of seven objectives have a comparable performance. Contrarily, in the on-site stormwater management system, five out of seven objectives have a comparable performance, hence the system has a high homogeneity. The COFAS method was tested in a case study for the urban drainage system in the municipality Kupferzell in Southwest Germany (Sieker et al. 2008b; Helm et al. 2009).

\subsection{Framework for detailed measurement of flexibility}

To cover the need for a more micro-level assessment of the benefits of flexibility for some LA members, an additional measurement approach was developed. The metrics for the measurement of flexibility are systematically developed from the definition of flexibility presented above (Hocke 2004). The first metric is the 'range of change', which indicates the range of future changes the system can cope with. 'High flexibility' is given when a wide range of future changes can be managed by the system. The second metric is the "lifecycle performance' of the system. Future alterations can result in the varying performance of a system over time. The better the performance and the higher the homogeneity for different future states, the higher the flexibility. The third metric is the 'costs of change'; the whole life-cycle-costs of the system include the initial investment costs, operation costs, damage costs and change costs caused by the adaptation of the system

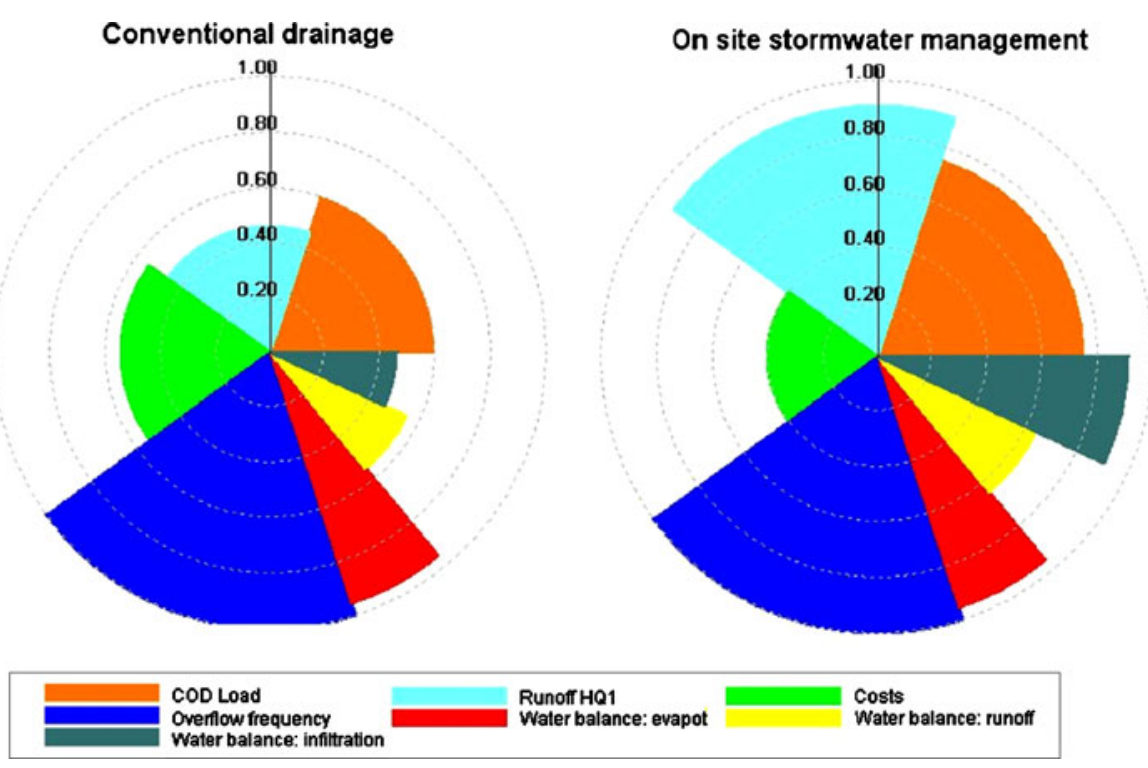

Fig. 1 COFAS Tool-Sector diagrams system performance for conventional drainage system and on site stormwater management system (Sieker et al. 2008b) 
Fig. 2 Framework of the different steps required for the measurement of flexibility
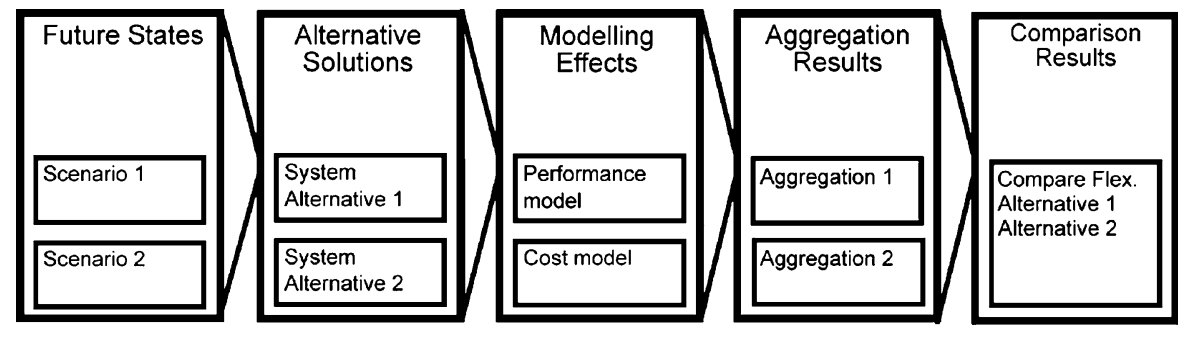

to future changes. The fourth metric is the 'duration of change', which describes the time-period that is required to adapt the system to new requirements. The shorter the duration of change and the lower the costs of change, the higher the flexibility.

The metrics are integrated in a framework for the measurement of flexibility (Fig. 2). The approach is based on the comparison of the systems performance of different alternative solutions with respect to different future states (de Neufville and Cardin 2008). To illustrate the approach to the LA, the framework was applied for a case study of an urban drainage system for a planned residential site with around 400 residents in Hamburg-Wilhelmsburg.

The framework for measuring flexibility includes the following steps:

- Future states: The future drivers for the urban drainage system, such as climate change and spatial development, are described. The vast number of possible future states is summarised into four future scenarios, each describing a hypothetical sequence of change drivers for the next 80 years. The first scenario describes a continuation of current conditions, the second scenario considers a sharp increase of runoff $(+70 \%)$, the third scenario includes a sharp decrease of runoff $(-40 \%)$ and the fourth scenario considers a medium increase of runoff $(+20 \%)$.

- Alternative solutions: The flexibility of different alternative solutions for the design of the urban drainage system is compared. Two alternative solutions, a conventional sewer system and a Sustainable Urban Drainage System (SUDS) are considered.

- Modelling the effects: For all alternative solutions and different future scenarios the system performance is modelled for the lifespan of 80 years. Two performance indicators are considered: the flooding frequency of the system and the flood protection in the receiving water body. These indicators are assessed with a hydrological model. Trigger levels are defined as minimum performance levels for the flooding frequency $(0,1$ floods/a) and flood protection (10\% increase of artificial annual runoff), at which the system must be adapted. The future scenarios are subdivided in time-steps of 20 years. At each time-step the performance is calculated and analysed to see if the performance falls below the trigger level and the system must be adapted to the changing conditions. The costs of change are described as the 'net present value' (Schierenbeck and Wöhle 2008) of the investment costs, operational costs, change costs and damage costs, which occur at the different time steps. Furthermore, the duration of change is documented.

- Aggregation results: The results of the different time-steps, different alternative solutions and different future scenarios are aggregated to one performance value per alternative solution. The different performance indicators are described by a utility value analysis, as a utility value between 0 and 100 (Peters et al. 2010). The performance of the different time-steps is summarized by the average performance (mean value) as well as by the homogeneity of performance (standard deviation) for each future scenario. Based on the $95 \%$ percentile, the maximum regret of the system performance for each alternative solution is calculated. The regret is the difference between the benefit of the assessed alternative solution and the maximal possible benefit if another alternative solution is chosen (Laux 2005). The maximum regret for each alternative solution for all the future scenarios is considered. Furthermore, the costs of change and the duration of change for each alternative solution are calculated. In addition, we documented the range of change for each alternative solution.

- Comparison results: The range of change and the regret of the system performance, the costs of 
Table 1 Results of the case study HamburgWilhelmsburg

\begin{tabular}{|c|c|c|c|c|c|}
\hline Flexibility metric & $\begin{array}{l}\text { Scenario } 1 \\
( \pm 0 \%)\end{array}$ & $\begin{array}{l}\text { Scenario } 2 \\
(+70 \%)\end{array}$ & $\begin{array}{l}\text { Scenario } 3(- \\
40 \%)\end{array}$ & $\begin{array}{l}\text { Scenario } 3 \\
(+20 \%)\end{array}$ & Total \\
\hline $\begin{array}{l}\text { Range of change } \\
(\%)\end{array}$ & & & & & Difference \\
\hline SUDS & 0 & 123 & -25 & 31 & 0 \\
\hline Sewer & 0 & 123 & 0 & 31 & -25 \\
\hline $\begin{array}{l}\text { Performance } \\
\text { (utility value) }\end{array}$ & & & & & $\begin{array}{l}\text { Max. } \\
\text { regret }\end{array}$ \\
\hline SUDS & 74 & 64 & 80 & 74 & 4 \\
\hline Sewer & 78 & 51 & 83 & 78 & 13 \\
\hline $\begin{array}{l}\text { Costs of change } \\
\text { (EUR) }\end{array}$ & & & & & $\begin{array}{l}\text { Max. } \\
\text { regret }\end{array}$ \\
\hline SUDS & 18,082 & 30,726 & 16,582 & 20,101 & 0 \\
\hline Sewer & 20,109 & 120,524 & 20,109 & 20,109 & 89,798 \\
\hline $\begin{array}{l}\text { Duration of change } \\
\text { (weeks) }\end{array}$ & & & & & $\begin{array}{l}\text { Max. } \\
\text { regret }\end{array}$ \\
\hline SUDS & 0 & 8 & 8 & 8 & 8 \\
\hline Sewer & 0 & 26 & 0 & 0 & 18 \\
\hline
\end{tabular}

change and the duration of change of the different alternative solutions, are documented in Table 1. SUDS minimises the regret of performance, the costs of change, the duration of change and maximises the range of change and hence is more flexible than the sewer system.

\section{Options for flexible design of urban drainage systems}

The LA members wanted to know how we could provide a flexible design for urban drainage systems. A key question is, whether or not conventional drainage systems, or SUDS, provide more flexibility. Conventional drainage systems, such as separated or combined sewer systems, are focused on the quick discharge of the runoff in the receiving body of water. On the contrary, SUDS consist of decentralised elements for the retention, infiltration and evaporation of stormwater with the goal to minimise the anthropogenic impact on the natural water cycle.

The LA question was addressed in two case studies. In the first case study in Hamburg, SUDS offer a significantly higher flexibility than the sewer system. Second the results of the Kupferzell case study (Sieker et al. 2008b) illustrates that SUDS offer a significantly higher degree of flexibility than sewer systems.
The high flexibility of SUDS could be traced back to different characteristics. SUDS consist of different modular elements like retention basins, infiltration swales, wetlands or infiltration-trench elements, which are compatible with each other and can be replaced or changed independently. In addition, the decentralised structure of SUDS facilitates the allocation of resources to locations that are most affected by change.

\section{Conclusions: perception by SWITCH Learning Alliance Hamburg}

The concept of flexible design for urban drainage systems was presented to the SWITCH LA Hamburg (Sieker 2008a; Eckart 2009). In general the LA members agreed with the idea of flexible design for urban drainage systems (Langenbach 2008). The concept of flexible design was observed as a suitable strategy to deal with problems observed in the Hamburg-Wilhelmsburg district, which are characterised by an increased vulnerability against future drivers. Flexible design offers the chance to make required decisions for urban drainage systems despite the future uncertainties. But there were also some concerns about the consequences of flexible urban drainage systems on urban design (Langenbach 2008). 
The LA members were particularly interested in the general recommendation that SUDS offer a higher flexibility than conventional sewer systems. SUDS offer a reliable drainage, are more environmental friendly and better suited for future unpredictable changes. Because SUDS are already mandatory for all new development sites in Hamburg, the recommendation is considered as support for the current strategy. To improve the uptake of flexible design for urban drainage systems, additional approaches and recommendations for the identification and optimisation of flexibility options are required.

Acknowledgments This research was supported by the SWITCH project (http://www.switchurbanwater.eu).

\section{References}

Ashley R, Blanksby J, Cashman A, Jack L, Wright G, Packman J, Fewtrell L, Poole T, Maksimovic C (2007) Adaptable urban drainage: addressing change in intensity, occurrence and uncertainty of stormwater (AUDACIOUS). Built Environ 33:70-84

de Neufville R, Cardin MA (2008) A survey of state-of-the-art methodologies and a framework for identifying and valuing flexible design opportunities in engineering systems, Working paper Massachusetts Institute of Technology, Cambridge

Eckart J (2009) Die Zukunft der dezentralen Regenwasserbewirtschaftung? (The future of decentralised stormwater management?). In: Gulyas H, Otterpohl R (eds). Hamburger Berichte zur Siedlungswasserwirtschaft 70-21, Kolloquium zur Abwasserwirtschaft Hamburg. 9 and 10 September 2009

Eckart J, Sieker H, Vairavamoorthy K (2010) Flexible Urban Drainage Systems, Water Pract Technol 5(4). doi: 10.2166/wpt2010.072

Helm B, Träckner J, Sieker H, Krebs P (2009) Flexibilität als Bewertungskriterium bei der Planung von Systemen der Regenentwässerung (Flexibility as decision criterion for the design of urban drainage systems). Korrespondenz Abwasser Abfall 56(4):372-381

Hocke S (2004) Flexibilitätsmanagement in der Logistiksystemtheoretische fundierung und simulation logistischer gestaltungsparameter (Flexibility management for logistics), Bayreuth
Kluge T, Libbe J (2006) Transformation netzgebundener Infrastruktur-Strategien für Kommunen am Beispiel Wasser (Transformation of network infrastructure-strategies for communities the example water). Difu-Beiträge zur Stadtforschung, Berlin

Langenbach H (ed) (2008) Make Water Visible and Useful-5. SWITCH Expert Forum-Szenarien und Indikatoren für ein integriertes Wassermanagement in Wilhelmsburg 2030 (scenarios and indicators for integrated urban water management in Wilhelmsburg 2030) (not published)

Laux H (2005) Entscheidungstheorie. Springer, Berlin, Heidelberg, New York

Maharjan M, Pathirana A, Gersonius B, Vairavamoorthy K (2009) Staged cost optimization of urban storm drainage systems based on hydraulic performance in a changing environment. Hydrol Earth Syst Sci 13:481-489

Peters C, Sieker H, Eckart J (2010) Assessing future uncertainties associated with urban drainage using flexible systems- the COFAS method and tool, SWITCH sustainable water management in the city of the future deliverable 2.1.4

Schierenbeck H, Wöhle C (2008) Grundzüge der Betriebswirtschaftslehre-Studienausgabe (General outline of business administration-study edition), München

Schmitt T (2006) Klimaveränderungen-Konsequenzen für die Siedlungsentwässerung? (Climate change-consequences for urban drainage?). GWF Wasser Abwasser 147:S210 S214

Sieker H (2008a) Entwicklungsfaktoren für die Zukunft der Siedlungsentwässerung (future drivers for the development of urban drainage). In: Langenbach $\mathrm{H}$ (ed) Make Water Visible and Useful-5. SWITCH Expert Forum-Szenarien und Indikatoren für ein integriertes Wassermanagement in Wilhelmsburg 2030 (scenarios and indicators for integrated urban water management in Wilhelmsburg 2030) (not published)

Sieker H, Helm B, Krebs P, Schlottmann P, Tränker J (2008b) Flexibility - a planning criterion for stormwater management. In: 11th international conference on urban drainage, Edinburgh, Scotland, UK

Vairavamoorthy K. (2009a) Wassermanagement in den Städten der Zukunft (Water management in the cities of the future) In: IBA 2009 IBA Internationale Bauausstellung Hamburg (ed) IBA Labor Klimafolgenmanagement: Herausforderung Wasser Dokumentation der Fachtagung 19, Hamburg, bis 21 Feb 2009

Vairavamoorthy K (2009b) Managing water for the city of the future. Int Rev Landsc Archit Urban Design 68:94-98

van der Steen P, Howe C (2009) Managing water in the city of the future; strategic planning and science. Rev Environ Sci and Biotechnol 8:115-120 